worried about the risk of drug dependence. They are likely to ask for psychological treatments, which are considered safer and more radical in dealing with the root cause of their illness. However, the majority of Arab patients have much less confidence in psychological or 'talking' therapies than in physical therapies.

During individual psychotherapy, it is advisable to punctuate individual sessions with Arab patients by joint sessions with key family members. This avoids the sabotage of any improvement of the individual by family members who have cast the patient in the sick role. In joint sessions with family members they are helped to accept the patient's assertiveness as a healthy development and are urged to continue supportive family relationships.

\section{References}

El-Islam, M. F. (1979) A better outlook for schizophrenics living in extended families. British Journal of Psychiatry, 135, 343-347.

El-Islam, M. F. (1994) Collaboration with families: an alternative to mental health legislation. Care in Place, 1, 256-260.

El-Islam, M. F. (1998) Clinical applications of cultural psychiatry in Arabian gulf communities. In Clinical Methods in Transcultural Psychiatry (ed. S. 0. 0 kpaku), pp. 155-170. Washington, DC: American Psychiatric Press.

El-Islam, M. F. (2001) The woman with one foot in the past. In Culture and Psychotherapy (eds W-S. Tseng \& J. Streltzer), pp. 27-41. Washington, DC: American Psychiatric Press.

El-Islam, M. F., Abu-Dagga, S. I., Malasi, T. H., et al (1986) Intergenerational conflict and psychiatric symptoms. British Journal of Psychiatry, 149, 300-306.

Kroeber, A. I. \& Kluckhohn, C. (1952) Culture: A Critical Review of Concepts and Definitions. Cambridge, MA: Harvard University Press.

\section{For contributions} to the

'Associations and collaborations' column, please contact John

Henderson, email: john.henderson53@ btopenworld.com

EFPT website: www.efpt.org

\title{
Twelve years old: the European Federation of Psychiatric Trainees (EFPT)
}

\section{Julian Beezhold}

President 2003-04, European Federation of Psychiatric Trainees; Crisis Resolution Home Treatment Team, Hellesdon Hospital, Drayton High Road, Norwich NR6 5BE, UK, email: julian.beezhold@nwmhp.nhs.uk

\begin{abstract}
The European Federation of Psychiatric Trainees (EFPT) is an independent federation of national trainee associations; it represents over 12000 trainees in 19 member countries across Europe. It is run by an annually elected board, comprising the President, Secretary-General, Treasurer, President elect and past President, and is governed by a written constitution.

The EFPT organises an annual forum, hosted by the current President, which is the policy-making body of the EFPT and which provides an opportunity for work on EFPT projects, academic discussion, networking and social interaction. Two official delegates represent each member country at the annual forum and each country has one vote. 0 ther trainees may attend and participate as observers.
\end{abstract}

\section{How did the EFPT start?}

In early 1992, a few members of the Collegiate Trainees' Committee (CTC) of the Royal College of Psychiatrists decided to build links between psychiatric trainees across Europe. They wrote to the embassies of all European countries to ask for information about trainee organisations. It became apparent that only three countries had a national psychiatric trainee asso ciation. However, contact was made with individual trainees in many countries and this led to an initial meeting in late 1992 in London. Sixteen trainees from nine different countries attended this informal meeting. A decision was taken to create the EFPT at an inaugural meeting in Utrecht, The N etherlands, in March 1993.

\section{Aims and objectives}

Although the aims and objectives of the EFPT have changed slightly over the years, the organisation was founded in order to do the following:

o promote representation of all psychiatric trainees

o build national trainee organisations

o provide a forum in which to learn about the diversity and richness of the current training of psychiatrists in Europe

o explore ways in which trainees can promote and improve their own training

o promulgate the opinion of the forum to relevant bodies

o promote the highest possible standards of treatment and care in psychiatry

o promote opportunities for trainees to do parts of their training, with full accreditation, in other European countries (the Exchange Programme)

O to develop policy, EFPT statements, by consensus on matters relevant to trainees.

\section{EFPT development}

The official launch ofEFPT in Utrecht in 1993 was followed by annual forums in Cork, Ireland (1994); Copenhagen, Denmark (1995); Lisbon, Portugal (1996); Athens, G reece (1997); G hent, Belgium (1998); Tampere, Finland (1999); Berlin, Germany (2000); N aples, Italy (2001); Sinaia, Romania (2002); Paris, France (2003) and Cambridge, UK (2004).

EFPT policy statements have been agreed and revised over the years on:

O general medicine and neurology in psychiatric training (1994)

O experience in research $(1994,1997,2001)$

o part-time training (1994)

o national trainees' organisations (1995)

O exchange of trainees between different countries (1995, 2001, 2002, 2003) 
O evaluation of knowledge $(1995,1999,2000)$

o quality oftraining - supervision and evaluation $(1995,2001$, 2002)

O training in child and adolescent psychiatry $(1996,2002)$

O psychotherapy training $(1996,1999,2001,2002,2003)$

o requirements for teachers (1996)

o quality assurance in training - independent inspection in training institutions (1997)

○ $\log \operatorname{books}(1997,1998)$

O removal of trainees from training (1998)

O mental health promotion (1999)

O independent appeal procedures for trainees (2002)

O training in community-based psychiatry (2002)

O old age psychiatry (2003)

o 'common trunk' (i.e. core training for all branches and specialties within psychiatry) (2004)

O the EFPT's relationships with other organisations (2004).

\section{The EFPT's achievements}

The establishment and long survival of the EFPT as an effective, growing and resilient independent European trainee organisation is the greatest achievement. There is no comparable international organisation of trainees in any other specialty.

The EFPT continues to establish links and collaborative working with the Union of European Medical Specialists (UEMS) through its participation in: the UEMS Board and Section of Psychiatry; the UEMS Section for Child and Adolescent Psychiatry; the Association of European Psychiatrists (AEP); and the joint World Psychiatric Association (WPA)/W orld Health O rganization (WHO )/UEMS/ AEP/EFPT Taskforce for European Leaders in Psychiatry.

At an international level, EFPT members have played a central role in the W PA Young Psychiatrists Council (W PA-YPC), founded in 2004, and the independent World Association of Young Psychiatrists and Trainees (WAYPT), founded in 2003.

Many EFPT policies have been adopted in the training programmes of European countries. While the EFPT certainly cannot take all the credit, it has been an influence in this process of improving training quality and conditions across Europe. Examples include EFPT policy (1996) on training in child and adolescent psychiatry for general psychiatrists, which was adopted in the UK in 1998; EFPT policy (1997) on the independent inspection of training institutions, which was piloted in Germany 2004; and EFPT policy (1996) on psychotherapy training, which is reflected in Chapter 6 of the UEMS Charter on Specialist Training (2003).

There were three national trainee associations in Europe in 1992. This has now increased to 19 national trainee associations, directly due to the influence of the EFPT. O ur 19 full member countries are: Austria, Belgium, D enmark, Estonia, Finland, France, Germany, Greece, Ireland, Italy, Latvia, The N etherlands, N orway, Romania, Slovakia, Spain, Sweden, Turkey and the UK.

Good practice has spread as we have learnt from each other; for example, the national introductory welcoming meeting for new trainees to psychiatry, long established in France, has inspired the launch of similar meetings in Ireland and the UK.

The EFPT has built a structure in which it is safe to disagree, while at the same time serving as a thriving model of international cooperation and collaboration. It has also actively developed leadership in psychiatry, with several former members of the EFPT now active on the boards of their national associations; one former EFPT President represents his/her country on the UEMS Board and Section of Psychiatry; and several present and former EFPT members are involved in the WPA-YPC and WAYPT, including in leadership roles.

\section{EFPT challenges - past, present and future}

The EFPT has developed from an organisation with typewritten documents, no email and no website, which communicated by telephone and post, into today's EFPT with a website (www.efpt.org), an open access listserve (efpt@ yahoogroups.com) for quick and simple discussion, and documents produced with word-processing software.

Money is always a problem, partly because the EFPT is an independent organisation that does not accept money directly from pharmaceutical companies, and partly because of the vast differences in salaries across countries. Trainees in Europe earn monthly salaries ranging from about $€ 40$ through to about $€ 7500$, depending on where they work.

Trainees soon complete their training and therefore leave the EFPT. Despite this, the EFPT's structure and practice have been effective in ensuring the right mix of experience and continuity, along with recruitment of new representatives.

English is used as the official language. This can impede discussion at times, although member countries tend to select delegates who are multilingual. Wording of policies has to be very carefully thought through and debated to ensure that the meaning is the same for all.

The EFPT's approach to differences in training is that we greatly value the diversity of training experiences in Europe, but we strive for the harmonisation of the quality of training. We are currently undertaking a Europe-wide 'Satisfaction Survey' to look at both the content and the experience of training from the point of view of trainees. We hope that this will provide really useful information that will help improve the quality of training.

\section{Further reading}

Mathis, D., Hanon, C., Porcheret, D., et al (2004) Les internes en psychiatrie et la construction européenne. Annales Médico Psychologiques, 162, 80-85.

Schulze, T. G. \& Treichel, K. C. (2002) The European Federation of Psychiatric Trainees (EFPT) - an integral part of the European harmonisation of psychiatric education and practice. European Psychiatry, 17, 300-305.

van Beinum, M. (1993) European trainees conference. Psychiatric Bulletin, 17, 96-97.

van Beinum, M. (1993) The European Forum for all Psychiatric Trainees. Psychiatric Bulletin, 17, 679-680.
Trainees in Europe earn monthly salaries ranging from about $€ 40$ through to about $€ 7500$,

depending on where they work. 